\title{
Numerical and real-life assessment of the moisture safety of CLT structure with PIR insulation composite under the Swedish climate
}

\author{
Yutaka Goto ${ }^{1, *}$, Holger Wallbaum ${ }^{1}$, Johan Olofsson ${ }^{2}$ and Ulf Norr $^{3}$ \\ ${ }^{1}$ Chalmers University of Technology, Department of Architecture and Civil Engineering, SE-41296 Gothenburg, Sweden \\ ${ }^{2}$ ZENERGY AB, SE-56832 Skillingaryd, Sweden \\ ${ }^{3}$ Labs2020, SE-11157 Stockholm, Sweden
}

\begin{abstract}
The building industry is a major contributor of $\mathrm{CO}_{2}$ emission. Wood construction is a good option for carbon storage among various construction alternatives. Considering the growing market of multi-story wooden building in Sweden, CLT (cross laminated timber) structure with an alternative insulation composite with PIR insulation and $\mathrm{MgO}$ board was proposed. In order to prove the applicability of this construction for moisture safety, the hygrothermal performance of the wall was measured in real life at HSB Living Lab (Gothenburg, Sweden) throughout 2019. Furthermore, a numerical model to analyse its performance by transient heat and moisture transfer analysis was created to predict the performance of the wall system. After the successful validation of the numerical model, a parameter study was carried out to investigate the moisture risk of the wall system in the case of extensive wetting of the CLT panel and in various areas in Sweden (Gothenburg, Stockholm, Lund, Karlstad and Luleå). The study showed a low mould growth risk either in the test at the living lab or in the feasibility study. The development of the technology should further focus on the cost-effectiveness and design of all the construction details for the future market application.
\end{abstract}

\section{Introduction}

\subsection{Background}

The building industry is a major contributor of the $\mathrm{CO}_{2}$ emission. There is an increasing need to replace the conventional materials with renewable and carbonneutral materials. Wood is a good option as trees absorbs $\mathrm{CO}_{2}$ from the atmosphere and stores them as material as long as it is used as wood.

In Sweden, there is a pressing need for more housing. Thus the multi-story wooden residential building is a growing sector. After the change of the fire regulation in 1994, the annual share of the wooden construction among the newly-built multi-story residential building has increased from $0 \%$ to more than $10 \%$. And it is expected to keep increasing in the coming decade.

There are various construction methods for multistory wooden residential buildings. The most common method the light frame timber construction when the height of the building is limited up to around 6 stories. Meanwhile, CLT (cross laminated timber) is one of the emerging materials in the wood construction sector. CLT consists of laminated layers of wood lamellas. CLT construction is suitable for higher construction due to its high load capacity, while CLT constructions tend to become more costly than other timber solutions.
Therefore, there is a need for solutions to make CLT constructions less costly. There are two major approaches to reducing costs. One is to simplify the construction process. The other one is to apply less expensive materials in other parts of the building.

As an alternative to achieve a simpler construction, the project team proposed the application of an insulation composite. It consists of two $\mathrm{MgO}$ (magnesium oxide) boards and PIR (polyisocyanurate) insulation in a sandwich structure. Hereafter the insulation composite is called PIC (PIR Insulation Composite). The product picture is shown in Fig. 1. $\mathrm{MgO}$ board is a relatively new material in the Nordic market. When $\mathrm{MgO}$ board was introduced primarily as a wind board around 2000, problems with saturated salt were reported especially in Denmark [1]. The project applied the $\mathrm{MgO}$ products which were free of saturated salt problems. As a composite, the PIC works as insulation board and wind barrier at the same time, and the element has a rigid form which makes it easy to handle in construction processes. Therefore it is expected that the application of the PIC in the building envelope can contribute to the simplification of the processes and it is a valid concept for CLT structures as well.

\footnotetext{
* Corresponding author: yutaka@,chalmers.se
} 


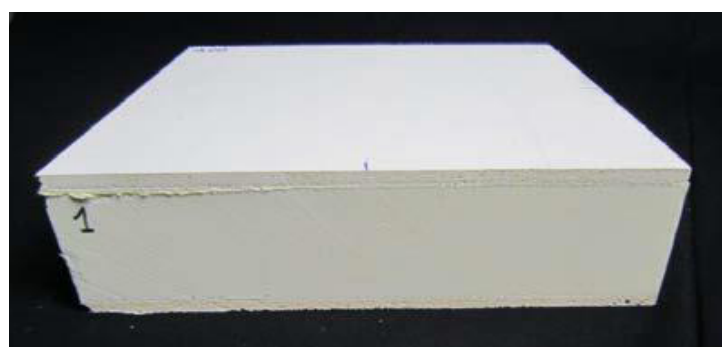

Fig. 1. The PIR insulation composite (PIC)

In order to prove the applicability of the construction in the Swedish conditions, it is necessary to empirically test the performance of the wall and validate the numerical model for the assurance of moisture safety to avoid the growth of mould and rot fungi. There are various ways to define the moisture safety of a building envelope. In this study, it was decided to refer to the requirement by BBR (Boverkets's ByggRegler), where the following is stated: "if the material moisture level for a material is not well-researched and documented, a relative humidity (RH) of $75 \%$ shall be used as the critical moisture level" [2].

\subsection{Goal of the project}

In order to evaluate the hygrothermal performance of the wall assembly with CLT panel and PIC (hereafter called "the wall assembly") and study the applicability of the system in various locations in Sweden, the following was carried out:

- Production of the mock-up of the wall assembly.

- Measurement of the hygrothermal performance in the real world.

- Simulation of the hygrothermal behaviour of the wall assembly and validation of the model by the measurement results.

- Simulation the moisture safety of the wall assembly under various climatic conditions in Sweden.

- Parameter study on initial moisture content of the CLT element to analyse the conditions of the construction with insufficient moisture protection.

\section{Real-world measurement of the hygrothermal performance of the wall assembly}

\subsection{Mock-up wall assembly}

The actual dimension of the mock-up of the wall assembly was 3220x1015x100 (CLT), 136 (PIC) mm with the corner cuts of $100 \times 100 \mathrm{~mm}$. The drawing is shown in Fig. 2. The CLT panel had a large penetrating hole (diameter of ca. $35 \mathrm{~mm}$ ) for carrying the panel with a crane and a rope. This hole was closed with expanding polyurethane foam. The U-value of this wall make-up is $0.168 \mathrm{~W} / \mathrm{m}^{2} \mathrm{~K}$.

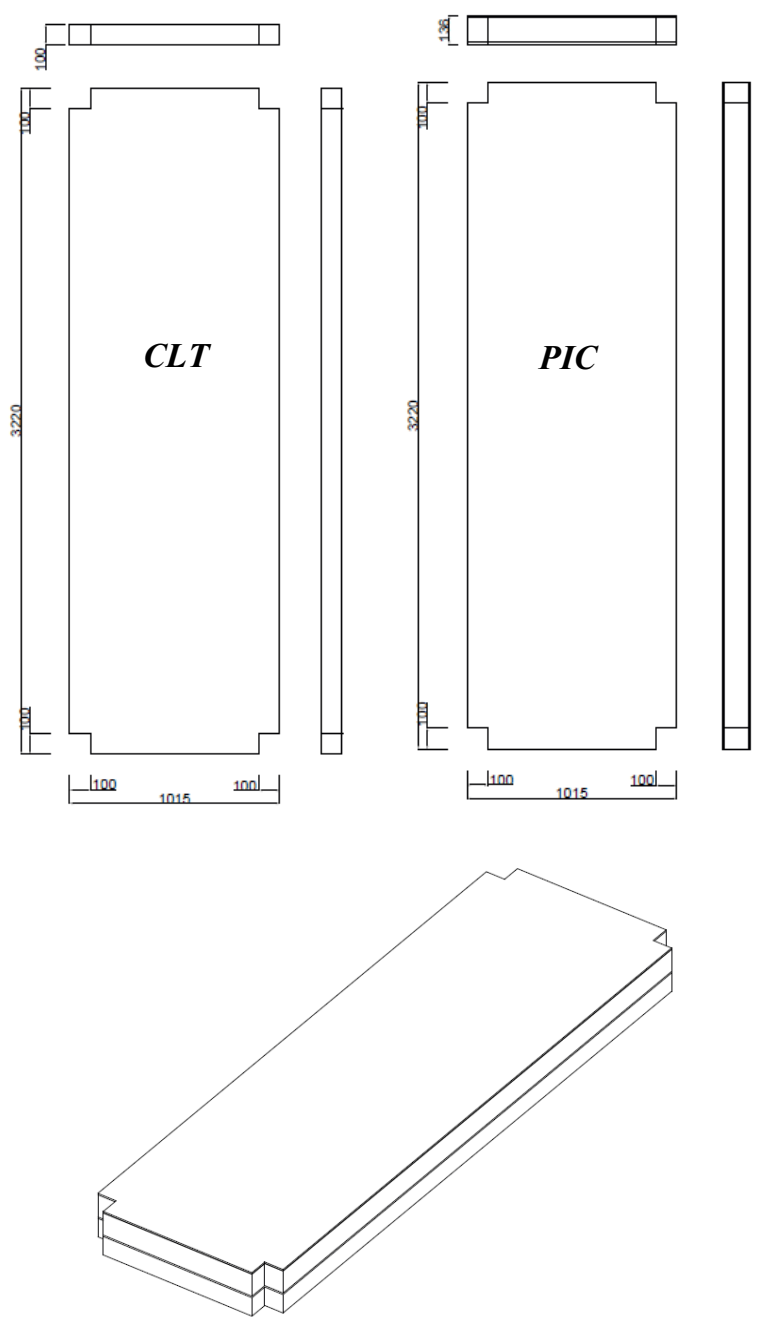

Fig. 2. Dimension (in mm) of each of the elements (top) and the illustration of the mock-up wall assembly (bottom).

The wall mock-up was assembled at the lab of Chalmers. The mock-up was fit into a timber frame which worked as the actual joint to the wall of the test site. The assembly work is presented in Fig. 3. In order to ensure the air-tightness between the timber frame and the mock up, the gap was tightly filled with selfexpanding sponge rubber.
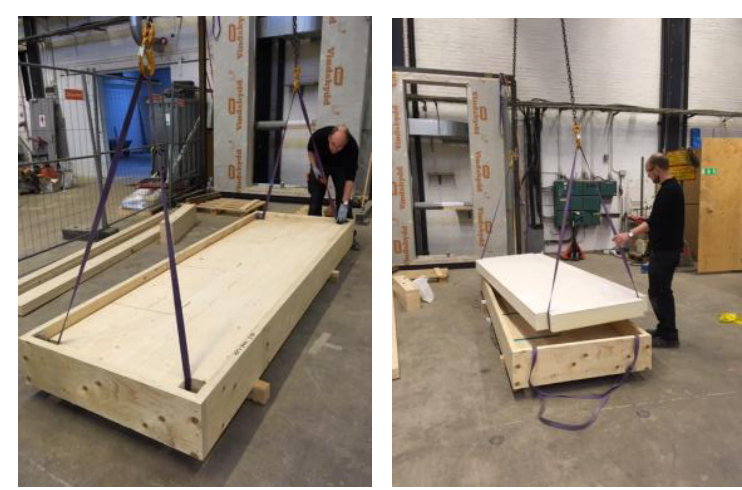

Fig. 3. The assembly of the mock-up. 


\subsection{Installation of the mock-up wall and sensors}

HSB Living Lab [3] was chosen as the test bed for the mock-up. HSB Living Lab is a four-storey building at the Johanneberg campus of Chalmers University of Technology in Gothenburg, Sweden. With its 29 apartments for up to 40 tenants and net floor area of $1720 \mathrm{~m}^{2}$, the building functions both as a student residence and a research infrastructure. HSB Living Lab offers a venue for various technical inventions for the construction industry [4]. Its exchangeable wall for new wall prototypes was identified as the best opportunity for the project to carry out the test with the real outdoor climate and an inhabitant in the room.

On January 7th-9th 2019, the mock-up wall was installed on site, where the CLT side faces the interior and the PIC side faces the exterior side. The installation work is shown in Fig. 4. The gap between the mock-up wall and the existing wall of the HSB Living Lab was filled with mineral wood and its interior side was sealed to ensure the minimum heat loss and air-tightness. The interior side of the prototype wall was covered by gypsum boards with an airgap so that the resident can start living in the apartment with no major visual disturbance. The exterior side was covered with a vapour-open, wind-tight and water-tight membrane, which was joint continuously to the same membrane of the surrounding existing wall part. The completion of the installation from the interior side is shown in Fig. 5. The wall is facing east-northeast.
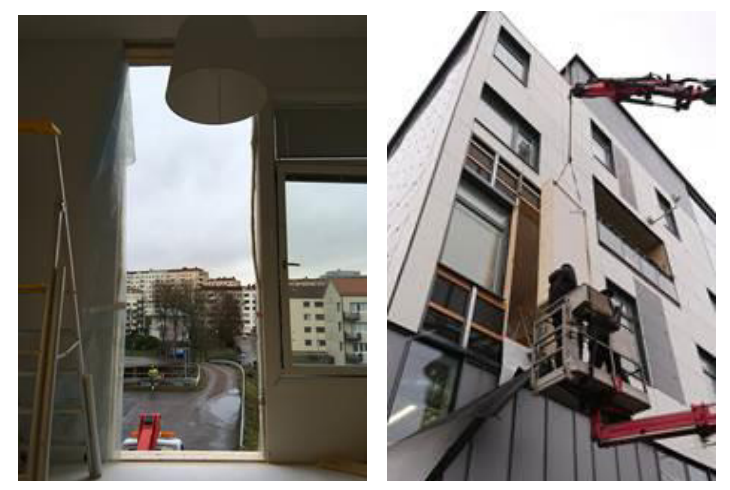

Fig. 4. Installation of the mock-up wall at HSB Living Lab.
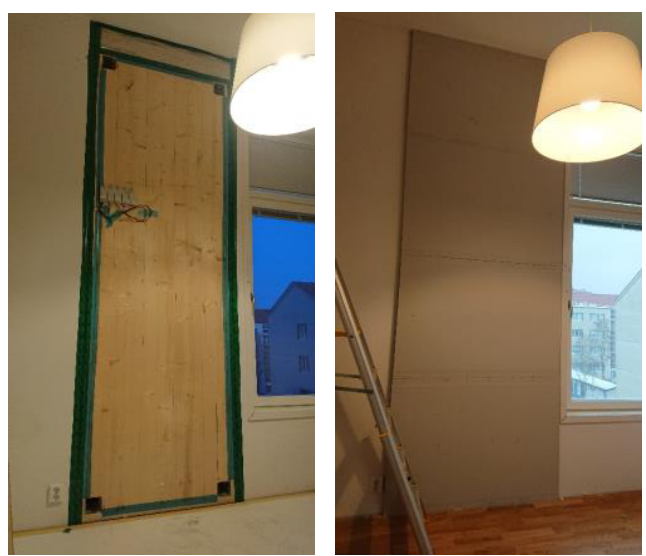

Fig. 5. The completion of the mock-up installation.

\subsection{Measurement}

In order to measure the hygrothermal performance of the wall, temperature and humidity sensors were installed in and on the wall mock-up; one sensor on the indoor surface (Celsicom TH500), one sensor on the outdoor surface and three sensors between CLT panel and the PIC (Celsicom TH501B, evenly distributed vertically in the middle of the panel). The installation inside the wall is shown in Fig. 6.

The monitoring of the hygrothermal performance of the wall started on 16.01.2019. The resident moved in on 14.02.2019.
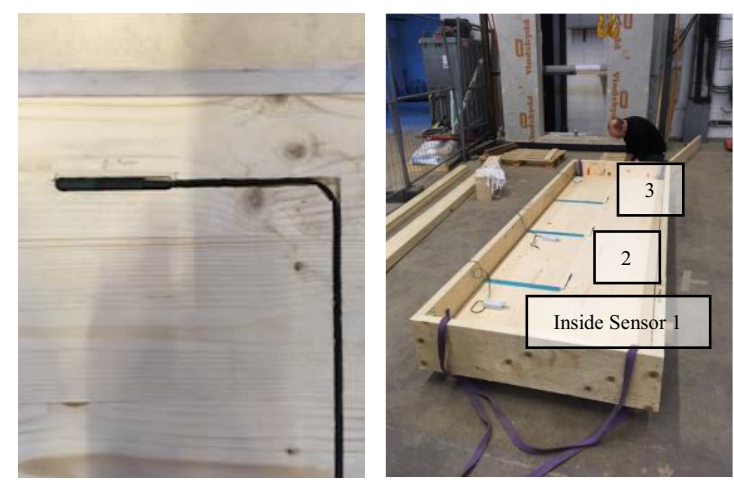

Fig. 6. Installation of temperature and humidity sensors.

\section{Numerical model of the wall assembly}

WUFI Pro $5.3^{\circledR}$ is one of the PC programs with which transient one-dimensional heat and moisture transport in multi-layered building components can be simulated [5]. In this program, the moisture transfer is based on vapor diffusion and liquid transport, and then two coupled equations for heat and moisture transfer are solved simultaneously. Several studies have been done for validating WUFI program, and they concluded that WUFI can be used for the prediction of the hygrothermal properties of layered assemblies [ex. 6]. Among numbers of limitation of the program, there is an uncertainty when calculating the moisture transfer under the condition with the continuous existence of liquid water. Since the focus of the measurement at HSB Living Lab was not to measure every single fluctuation but the overall behavior of the humidity without direct contact to liquid water, in this study, this program has been considered as adequate.

Problems due to the accumulation of the moisture inside the wall assembly would be located where there is moderate temperature and relative humidity for mold growth during a long enough time [7]. In this wall assembly, it is most likely between the CLT pane and the $\mathrm{PIC}$ as there is a significant change in vapor permeability and other hygrothermal properties.

\subsection{Input values for material properties}

The material properties required in this calculation method regarding heat and moisture transfer are as follows:

- Thickness 
- Moisture-dependent thermal conductivity

- Moisture storage function (sorption isotherm)

- Moisture-dependent water vapor diffusion resistance factor

- Bulk density in dry condition

- Specific heat capacity

- Liquid transport coefficient

- Overall porosity

Regarding the CLT panel, the existing data set in the software for "KLH Massivholz" was applied from the material database. Regarding the PIC, the following input values was applied based on measurements and standard values. Thermal conductivity was set at 0.024 $\mathrm{W} / \mathrm{mK}$ (constant). Moisture storage was set at 0.02 $\mathrm{kg} / \mathrm{m}^{3} \quad(10 \% \mathrm{RH}), \quad 0.2 \mathrm{~kg} / \mathrm{m}^{3} \quad(50 \% \mathrm{RH}), \quad 0.76 \mathrm{~kg} / \mathrm{m}^{3}$ $(80 \% \mathrm{RH}), \quad 1.64 \mathrm{~kg} / \mathrm{m}^{3}$ (90\%RH) and $9.72 \mathrm{~kg} / \mathrm{m}^{3}$ $(97 \% \mathrm{RH})$. Vapor diffusion resistance factor ( $\mu$-value) was set at 51.5 (constant between $0 \% \mathrm{RH}$ and $10 \% \mathrm{RH}$ ) and $29.9(100 \% \mathrm{RH})$ (linear change between $10 \% \mathrm{RH}$ and $100 \% \mathrm{RH})$. Bulk density was set at $26.5 \mathrm{~kg} / \mathrm{m}^{3}$. Specific heat capacity was set at $1470 \mathrm{~J} / \mathrm{kgK}$. Liquid water transport coefficient was set at 0 with the assumption that there is no liquid water in the system. Porosity was set at $0.99 \mathrm{~m}^{3} / \mathrm{m}^{3}$. The air permeability of the CLT panel was assumed at 0 . There could be situations that the surface layer has small cracks or small gaps between lamellas in the same layer. In fact the requirement for CLT production by EN16351 [8] allows a maximum 6 $\mathrm{mm}$ gap between neighboring lamellas. However, when producing the mock-up wall, the gaps between the lamellas of the surface layers and the integrity between the different layers were carefully observed and no significant gaps were found.

The input data of $\mathrm{MgO}$ in the WUFI model was substituted by the data of general gypsum board in the software's database with the assumption that the hygrothermal properties are similar to each other. As the $\mathrm{MgO}$ boards on the surfaces are homogenous and had no crack, the air permeability of the PIC was assumed at 0 . Even if the CLT panel had a think crack, gap or hole which penetrates thought the whole section

\subsection{Model geometry and other input details}

The thickness of the MgO board, PIR board and CLT panel was set at $8 \mathrm{~mm}, 120 \mathrm{~mm}$ and $100 \mathrm{~mm}$ respectively. The façade of the building (cladding and the ventilated air layer under the cladding) was not considered in the model geometry. Instead, the solar radiation and rainwater factors were translated into surface coefficients (see the following paragraphs for the details). The mesh of the finite volume model is shown in Fig. 7.

In order to carry out the calculation of the temperature and relative humidity in the wall model, it is necessary to give the input of the indoor and outdoor climate as the boundary condition. As the purpose of the simulation is to replicate the actual real-world measurement at HSB Living Lab, the measured climatic conditions (temperature and relative humidity) of the indoor and outdoor side of the ambient air was used as the boundary condition. Fig. 8 and 9 shows the actual boundary condition inputs for outdoor and indoor conditions respectively.

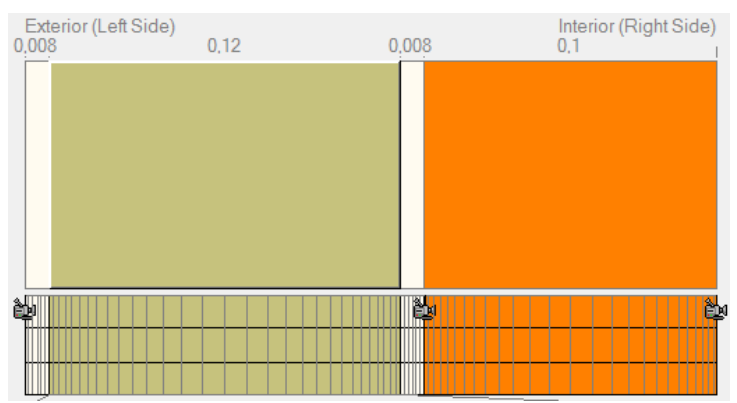

Fig. 7. 1 Dimensional geometry Mesh division of the finite volume model of the PIC wall assembly.

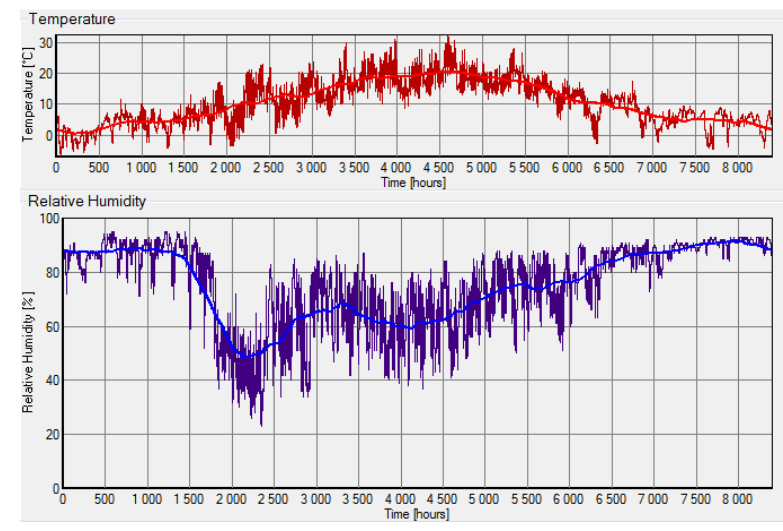

Fig. 8. Outdoor climate as the calculation boundary condition.

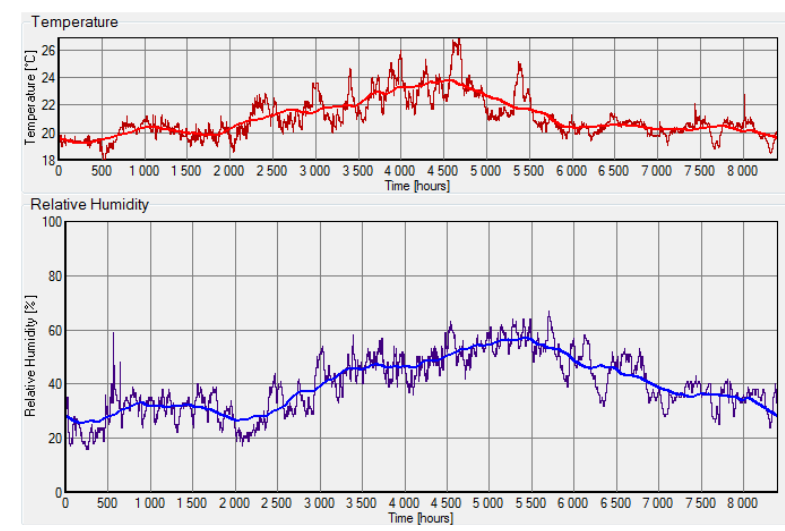

Fig. 9. Indoor climate as the calculation boundary condition.

The initial temperature of all the layers was set at 16 ${ }^{\circ} \mathrm{C}$. The initial relative humidity was set at $40 \%$ as an intermediate value of largely fluctuating values on both outdoor and indoor side. The standard surface heat resistance coefficient was set at $0.04 \mathrm{~W} / \mathrm{m}^{2} \cdot \mathrm{K}$ and 0.125 $\mathrm{W} / \mathrm{m}^{2} \cdot \mathrm{K}$ on the interior and exterior surface respectively. The surface $\mathrm{S}_{\mathrm{d}}$-value was set at $0 \mathrm{~m}$ as there is no significant vapour resistance on both surfaces.

For the exterior surface, short-wave radiation absorptivity and long-wave radiation emissivity were set at 0 as the surface of the wall was covered by the façade of the building. Rainwater absorption factor was set at 0 for the same reason. For the interior surface, short-wave 
radiation absorptivity, long-wave radiation emissivity and rainwater absorption factor were set at 0 since these are irrelevant for the interior surface.

\section{Result and discussion}

\subsection{Results of the real-world testing}

The measured temperature and relative humidity from the start of the measurement till Dec $31^{\text {st }} 2019$ are presented in Fig. 10 and 11 respectively. Those data from the sensors between the CLT panel and the PIC are given as "Inside 1", "Inside 2" and "Inside 3". It can be seen that those three sensors detected almost the same values for both temperature and relative humidity. This means that there was no major variation in the hygrothermal performance when comparing the different positions distributed vertically. It can be seen that the temperature inside the wall follows the fluctuation of the interior temperature while the relative humidity stays very stable. This shows that contribution of the moisture buffering by the CLT panel to largely slow down the humidity fluctuation of the indoor air.

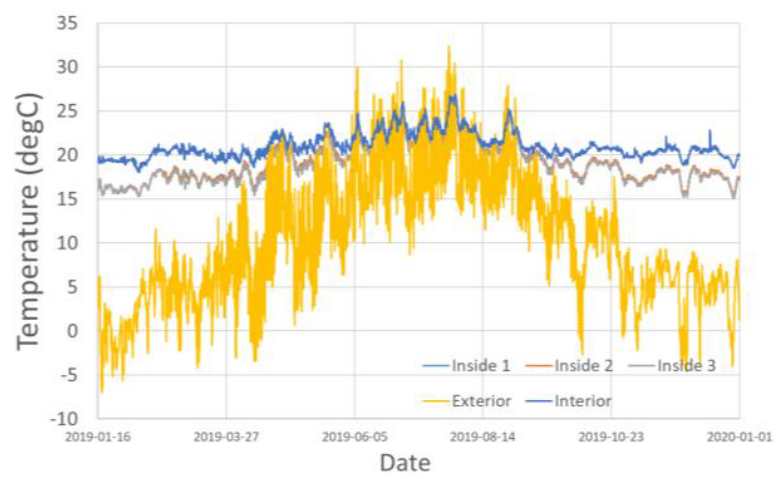

Fig. 10. Measured temperature.

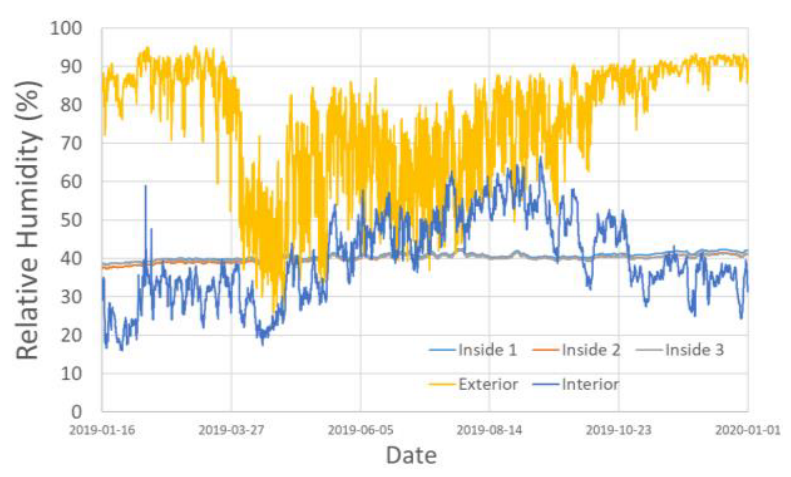

Fig. 11. Measured relative humidity.

\subsection{Comparison between the measurement and the simulation}

By giving the measured temperature and relative humidity of the indoor and outdoor air (see Fig.8 and 9), the temperature and relative humidity between the CLT panel and the PIC was calculated by WUFI. Fig. 12 and 13 shows the comparison of the results of the measurement and calculation for temperature and relative humidity respectively. As for the temperature, it was shown that the calculation by WUFI could predict the actual temperature values very precisely. As for the relative humidity, the calculation showed more dynamic variation over the year. It is assumed that this is due to the lack of moisture buffering consideration in WUFI. The difference between the measurement and the calculation was $6.1 \%$ at maximum, which is still well within the acceptable level of calculation accuracy.

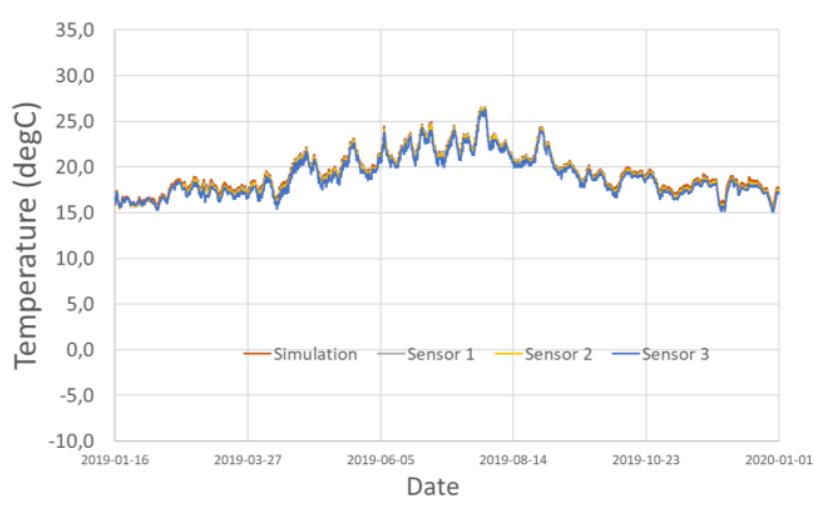

Fig. 12. Comparison of measured and simulated temperature values.

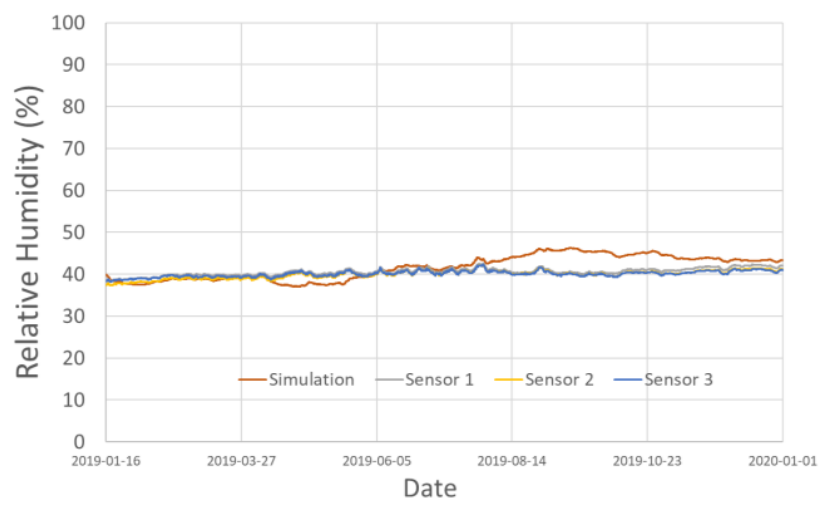

Fig. 13. Comparison of measured and simulated relative humidity values.

\subsection{Parameter study on initial moisture condition}

The results of the previous section was based on a dry condition, which could be achieved by careful control of the moisture content of the CLT panel by avoiding accidental wetting of the panel when handling for transportation and storage and a construction with a proper weather protection (construction tent etc.). In order to analyse a risk situation, a parameter study with the assumption of severe case of wetting of the CLT panel was carried out.

The scenario of the wetting is the following. The load bearing frame (CLT panels) of the building is built up on site with no protective tent. There is only minimum prefabrication of the panels, namely only the 
precut for joints and openings is done prior to the shipping to the construction site. This results in the extended time of the construction work on site and thus extensive wetting on the floor surfaces. The walls are built on wet surface of the floor, and so the bottom of the wall gets significant capillary suction of free water and both sides of the walls get wet from the rain. The analysis in this section focused on the moisture on the outer surface of the wall panel which would be covered by the PIC upon the installation of the insulation and the capillary water at the bottom of the wall because this has a less drying potential than the moisture on the inner surface of the wall and the floor surface.

Liisma conducted a measurement of the moisture content of CLT panels under a cold and wet condition in the suburb of Tallinn, Estonia [9]. A vertical CLT panel (initial moisture content by mass of ca. $10 \% \mathrm{~m}$, thickness of $60 \mathrm{~mm}$ ) with no covering was exposed to the natural weather condition with total precipitation of $52 \mathrm{~mm}$ for 6 weeks. The average moisture content of the most moist period at the depth of $10 \mathrm{~mm}$ from the panel edge was ca. $20 \%$ and that at the depth of $80 \mathrm{~mm}$ was ca. $25 \%$. The higher moisture content at the deeper point was observed due to the capillary suction of the free water. Based on this result, the initial moisture content of the CLT in a wet model was set at $25 \%$ and temperature of $16^{\circ} \mathrm{C}$.

Following was the other inputs for the parameter study: The climate data of Gothenburg was from the WUFI climate database (Lund University database for 1995-2005) was applied on the exterior surface. The start date of the calculation was set at 00:00 on September 1 st. The simulation time step was set at 1 hour and the total number of time step was set at 43800 ( 5 years). The wall orientation was set at North to minimize the influence of solar radiation. The indoor climate was defined by adjusting the outdoor climate by the procedure of EN 15026 with normal moisture load [10]. The surface transfer coefficients were the same as the model in 3.2.

Figure 14 shows the temperature and relative humidity between the CLT panel and the PIC over the 5year period. I showed that the it takes more than 1 year for the CLT panel to dry below 75\% RH.

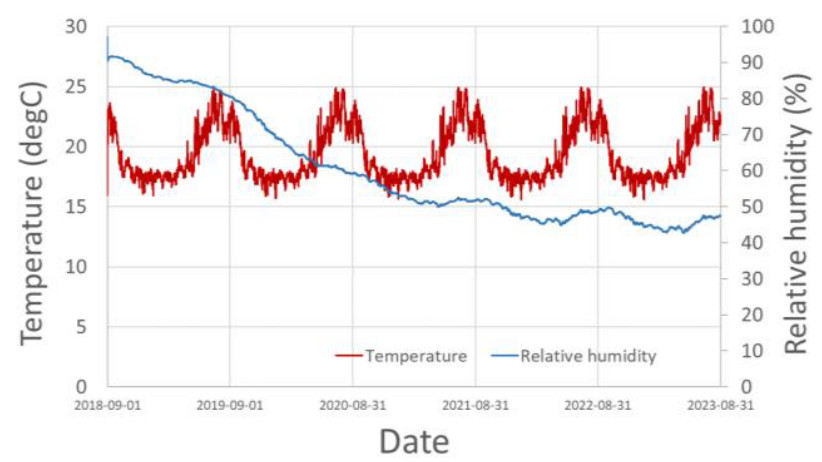

Fig. 14. Calculated temperature and relative humidity between a wet CLT panel and the PIC for 5 years in Gothenburg.
As the drying of the built-in moisture on the wall surface takes long time, it is necessary to further analyse the mould growth potential in order to evaluate the moisture safety of the construction in the case of extensive wetting. Therefore Mould Model by Hukka et al. [ex.11] was applied. By applying this empirical model, the risk of mould growth under given temperature and relative humidity conditions is expressed in Mould Growth Index (MGI) from 0 to 6, where 0 indicates no growth and 6 indicated (almost) full coverage of the surface by mould. The model considers the mould sensitivity of the materials, surface roughness etc. while it does not consider the $\mathrm{pH}$ value of the material surface or surface cleanness etc. The model of the response to fluctuation of the relative humidity is also limited as it concerns both the air humidity and the hygroscopic response of the substrate material. The model does not consider the substrate response to the humidity fluctuation (ex. moisture buffering). The acceptable MGI level depends on the situations of the focused surfaces. While the interior surface of the wall should not have MGI higher than 1 (small amounts of local growth to be detected under microscope), the exterior surface may allow MGI of up to 3 (visual growth with less than $10 \%$ of the surface coverage). When it comes interstitial surfaces in the wall structure, which has no direct connection to the interior air and is inner side of the air-tight membrane, the acceptable MGI shall be lower than 2 (several local growth to be detected under microscope).

Figure 15 shows the MGI of the surface of the CLT panel under the PIC for the whole simulation period of 5 years. The material parameter in the model was set according to the characteristics of a planed spruce heartwood with no surface treatment/coating. The model gave 1.75 as the maximum MGI, which indicates a relatively small growth during the drying period. After one year, the MGI declines linearly to 0 and it stays. Therefore, it can be said the wall has a sufficient drying potential to avoid significant mould growth after the wetting of the CLT panel by rainwater during the construction period.

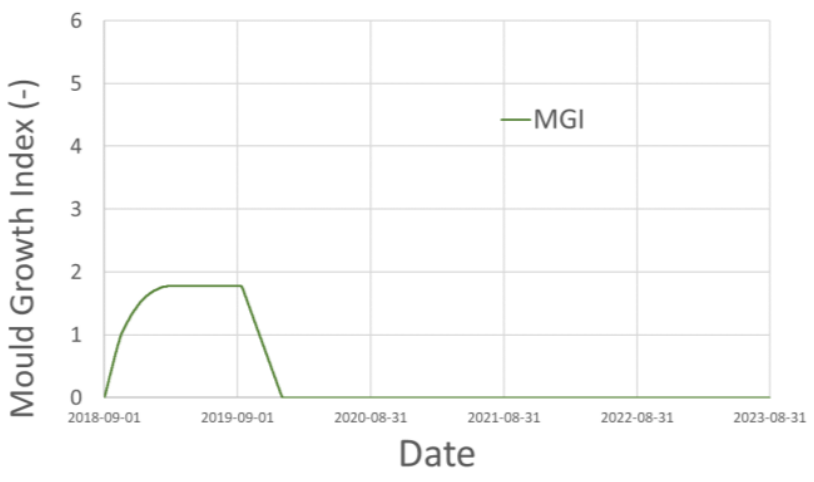

Fig. 15. Mould Growth Index (MGI) on the surface of a wet CLT panel under the PIC for 5 years in Gothenburg.

The above analysis assumed a rather bad case of wetting of the wood element. However, when considering a more efficient construction method, it is more realistic to prefabricate the wall panel or the room 
module in a factory before shipping to the construction site. In fact, such prefabrication is becoming more and more common in the wood construction industry in the recent years. By doing so, the wetting risk of the outer surface of the CLT panel would be minimized. Furthermore, various alternatives for protective tents of the construction site are available in the Swedish market, and a careful planning of it may keep the additional cost to the affordable level [12]. When having such a protective tent and prefabrication of the elements, it is assumed that the magnitude of wetting would be lower than this parameter study even in the case of accidental wetting except for continuous leakages inside the wall. Therefore it is concluded that the wall system itself has a sufficient drying potential and thus safe in terms of mould growth.

\subsection{Feasibility study with various climatic conditions}

As discussed in 4.2, the WUFI calculation showed a high accuracy on the prediction of the hygrothermal behaviour of the wall assembly. Therefore it is reasonable to evaluate the performance of the wall just by calculations with various climatic conditions with the assumption of a dry construction conditions. In this feasibility study, Gothenburg (west coast), Stockholm (east coast), Lund (south), Karlstad (middle) and Luleå (north) were chosen to represent various climatic zones of Sweden. The climate data of each city was imported from the WUFI climate database (Lund University database for 1995-2005). The input values for the models were the same as the parameter study in 4.3 except for the initial condition, which was set at $40 \% \mathrm{RH}$ of the ambient air and $16^{\circ} \mathrm{C}$ throughout the whole wall cross section.

Figure 16. 17, 18, 19 and 20 show the calculated temperature and relative humidity between the CLT panel and the PIC for Gothenburg, Stockholm, Lund, Karlstad and Luleå respectively. It was shown that the relative humidity does not exceed the critical value $(75 \%)$ in any case. Therefore it can be said that the inside of the wall is moisture safe under the Swedish climatic conditions given that the structure is not subject to a water leakage.

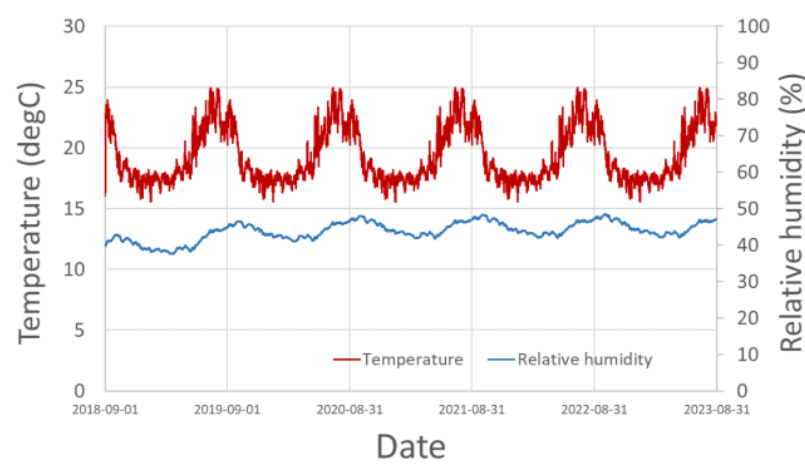

Fig. 16. Calculated temperature and relative humidity inside the wall for 5 years in Gothenburg.

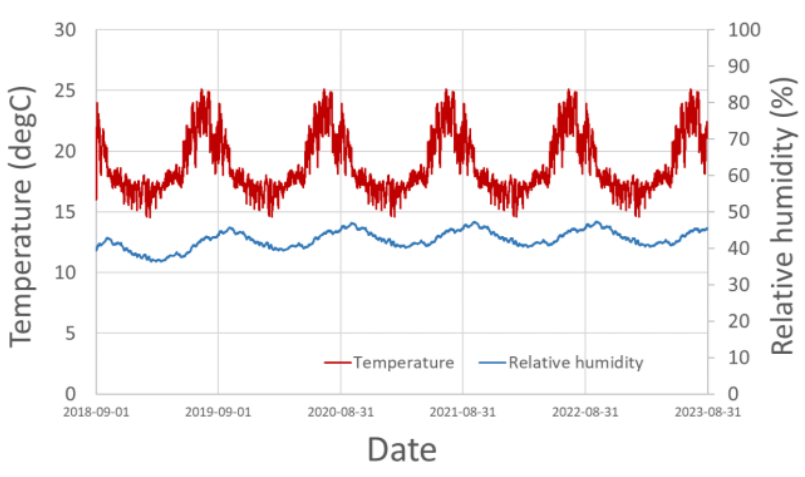

Fig. 17. Calculated temperature and relative humidity inside the wall for 5 years in Stockholm.

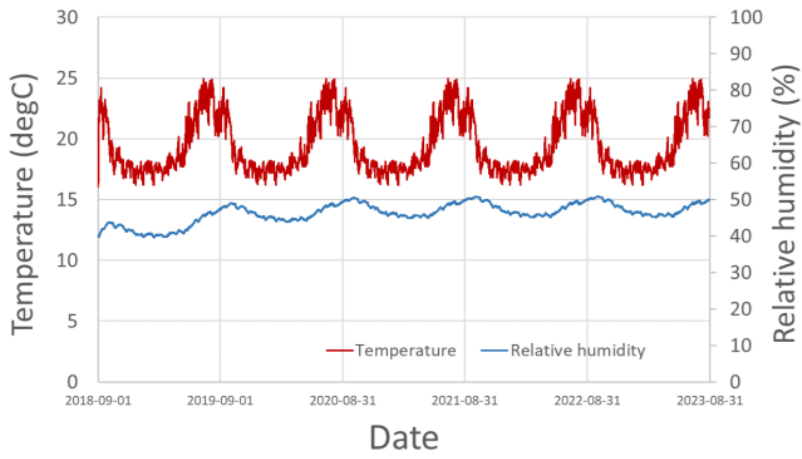

Fig. 18. Calculated temperature and relative humidity inside the wall for 5 years in Lund.

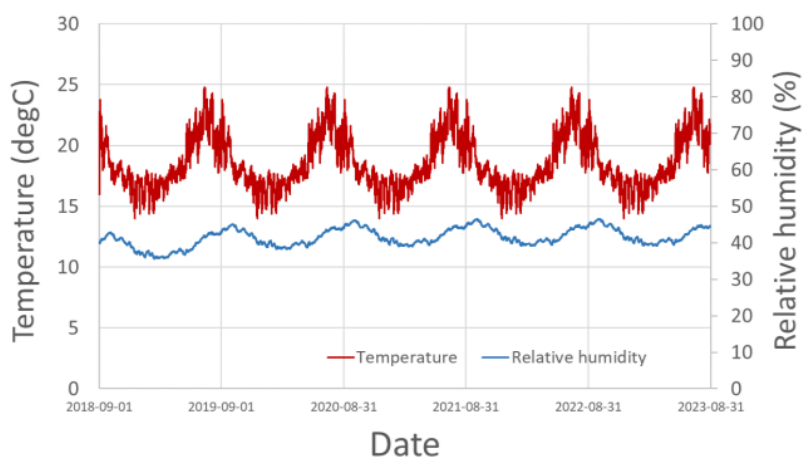

Fig. 19. Calculated temperature and relative humidity inside the wall for 5 years in Karlstad.

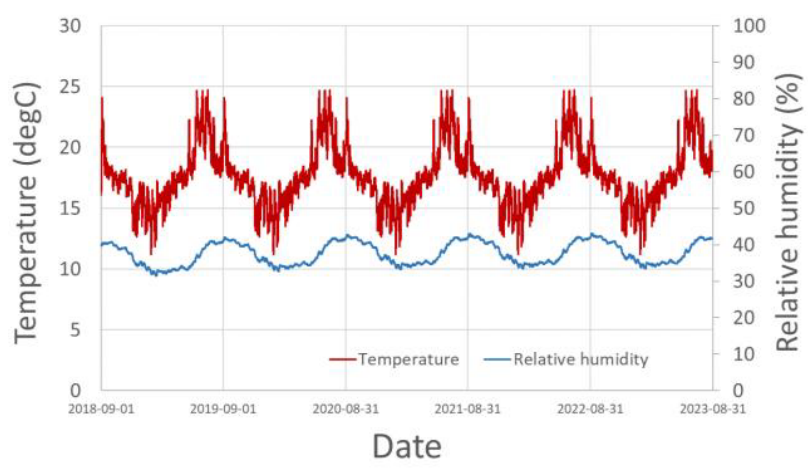

Fig. 20. Calculated temperature and relative humidity inside the wall for 5 years in Luleå. 


\section{Conclusion}

The project team designed the configuration of the wall assembly of CLT and PIR insulation composite and produced a full-size mock-up. The mock-up was tested at the HSB Living Lab with the real-world climate condition and the temperature and relative humidity inside the wall was measured. The measured values were compared to those which were calculated by transient heat and moisture transfer simulation program WUFI.

The comparison between the real-life measurements and calculations showed very good accuracy of the simulation. A sufficient drying potential and low mould growth risk was shown by a parameter study to evaluate the mould risk after an intensive exposure to rainwater during the construction period. The model was further applied to the feasibility study under various climatic conditions of Sweden. It was shown that inside of the wall does not have a mould growth risk due to the accumulation of moisture under the climate of Gothenburg, Stockholm, Lund, Karlstad and Luleå. Therefore is it concluded that the wall can be used in Sweden widely with mould growth risk with the condition that the structure is not subject to a water leakage. The construction process should anyway carefully plan the protection of the structure from rainwater in order to avoid undesirable water intake. It will also ensure the CLT panels to have minimal surface cracks due to wetting and uneven drying across the section. By preventing the major cracks, the hygrothermal property of the whole wall system can be better retained.

As the hygrothermal behaviour of the wall is evaluated as safe with some conditions, the development of the technology should focus on the cost-effectiveness and design of all the construction details. Once these are proven to be competitive against conventional solutions, the wall assembly system shall be ready to be applied in the market.

The cost analysis shall be done by comparing an equivalent building (multi-story apartment) design in three scenarios: (1) the project's wall assembly system, (2) CLT and conventional insulation and (3) reinforced concrete. In order to make the study more realistic, the cost comparison may require the development of joint solutions of the wall assembly system (not only the joint of the panels but also an overall joint system for all building components in different parts of the building).

Vinnova is acknowledge for the research fund for the project "WoodXZIP". Fristad Bygg (Mr. Adam Kihlberg) is acknowledged for providing insights for the joint design of the wall system the CLT panel for the mock-up wall. Mr. Tommie Månsson (research engineer at Chalmers) is also acknowledged for the lab works for the mock-up testing. HSB is acknowledged for the cooperation in the test at HSB Living Lab. The project team also espresses the great gratitude to the resident of the room with the installation of the test wall.

\section{References}

1. C. Rode, T. Bunch-Nielsen, K. Kielsgaard Hansen, B. Grelk. Energy Procedeia. Vol.132, PP.765-770 (2017).

2. The National Board of Housing: Boverket's Building Regulations. Available at online: http://www.boverket.se/ (accessed on 17/01/2020)

3. https://www.hsb.se/hsblivinglab/ (accessed on 17/01/2020)

4. A. Sasic Kalagasidis, S. Hagy, C Marx. Informes de la Construcción Vol. 69, 548, e224 (2017).

5. H.M. Künzel. Simultaneous heat and moisture transport in building components. One- and two dimensional calculation using simple parameters. IRB Verlag (1995).

6. Y. Goto., K. Ghazi Wakili, Y. Ostermeyer, A. Sasic Kalasidis, H. Wallbaum. Building and Environment, Vol.110, PP55-64 (2016).

7. H. Viitanen. Holzforschung 51(1), PP6-14 (1997).

8. CEN - EN16351. Timber structures - Cross laminated timber - Requirements (2015).

9. E. Liisma. Journal of Sustainable Architecture and Civil Engineering, Vol.2, No.25, pp.53-62 (2019).

10. EN 15026, Hygrothermal performance of building components and building elements - Assessment of moisture transfer by numerical simulation (2007).

11. A. Hukka, H. Viitanen. Wood Science and Technology, Vol.33, No.6, pp.475-485 (1999).

12. E. Brycke, L. Martinsson. SBUF 13499 Slutrapport - Väderskydd, En lathund för entreprenören (2019). 